\title{
Airborne multispectral identification of individual cotton plants using consumer-grade cameras
}

\author{
John K. Westbrook ${ }^{a c}$, Ritchie S. Eyster ${ }^{a}$, Chenghai Yang ${ }^{b}$, Charles P.-C. Suh ${ }^{a}$ \\ aUDA, ARS, Insect Control and Cotton Disease Research Unit, $2771 \mathrm{~F}$ and B Road, College Station, TX \\ 77845, USA (john.westbrook@ars.usda.gov; ritchie.eyster@ars.usda.gov; charles.suh@ars.usda.gov, \\ respectively)
}

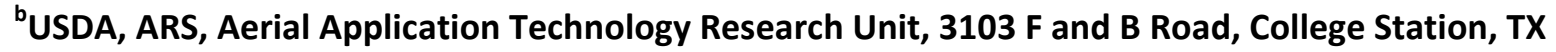 77845, USA (chenghai.yang@ars.usda.gov)

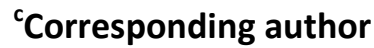

\begin{abstract}
Although multispectral remote sensing using consumer-grade cameras has successfully identified fields of small cotton plants, improved detection sensitivity is needed to identify individual or small clusters of cotton plants that also can provide habitat for boll weevils. The imaging sensor of consumer-grade cameras is based on a Bayer pattern, which alternates red, green, and blue filters over individual sensor pixels. However, each pixel of the imaging sensor of consumer-grade cameras represents direct measurement of only one of the three spectral bands (red, green, and blue) and interpolation of the remaining two spectral bands. We present an analytical technique in which endmember sets were derived from bimodal histograms of each spectral band for cotton, other vegetation types and soil, and linear spectral unmixing was used to identify individual cotton plants. We achieved significant misclassification rates as low as 0.125 and 0.146 in frequently tilled plots for validation tests of remote sensing identification of volunteer okraleaf cotton plants and volunteer conventional cotton plants, respectively. Results of this study indicate that consumer-grade cameras can acquire multispectral images of sufficient quality to detect individual cotton plants at an early growth stage, which will aid boll weevil eradication programs in identifying and locating volunteer plants.
\end{abstract}

Keywords Remote sensing, linear spectral unmixing, volunteer cotton, regrowth cotton, insect pest management

\section{Introduction}

The boll weevil, Anthonomus grandis (Boheman), is a pest of cotton for which an eradication program in the USA has nearly been completed. After a century of efforts to control boll weevil infestations in USA cotton fields, only a remnant population of weevils in the Lower Rio Grande Valley production area of southern Texas. The eradication program functions by mapping all cotton fields, using pheromone traps to detect incipient weevil populations, and applying insecticides when and where justified by weevil captures or as preventive measures. Where cotton plants are grown in temperate regions, winter freezes kill the cotton stalks following harvest. However, in subtropical regions cotton plants must be destroyed after harvest to prevent regrowth of cotton fruit on which weevil populations can survive and reproduce until the ensuing cotton production period (Summy et al., 1986). Also, volunteer cotton 
plants can germinate from seed that remains in a field after harvest or that is inadvertently scattered by floods or by transport of harvested cotton to gins.

Volunteer and regrowth cotton plants must be located and destroyed to reduce the risk of sustaining remnant weevil populations, otherwise undermining the success of intensive eradication programs. For example, fruit from 80 volunteer cotton plants on one farm in southern Texas were found to have produced more than 500 boll weevils (Troxclair, 2010). However, volunteer and regrowth cotton plants are difficult to locate because they can be distributed within a large cotton production region or can be hidden by other vegetation.

Typically only the field perimeter is visually inspected for the presence of volunteer and regrowth cotton plants. Consequently, plants occurring in the center of large fields generally escape detection. Further, volunteer and regrowth cotton plants are typically obscured by the primary crop until crop senescence, defoliation or harvest. There is a lack of alternatives for detecting volunteer and regrowth cotton plants.

Although cotton producers are required to report the location of planted cotton fields to the USDA Farm Services Agency, this information is either unavailable or belatedly available to the boll weevil eradication program. However, airborne remote sensing has the capability to rapidly identify early growth of cotton fields (Bai et al., 2011) and volunteer and regrowth cotton plants within large regions. Yang et al. (2011) assessed defoliation treatments using remote sensing technology to detect regrowth of treated cotton plants. Further, enhanced detection of cotton plants relative to other crops using remote sensing has been achieved by applying discriminant analysis of spectral properties of plants (Zhang et al., 2012) and by incorporating ground-based measurements (Zhang et al., 2013).

We evaluated the capability of airborne multispectral detection of individual volunteer and regrowth cotton plants -- both conventional and okraleaf varieties -- using consumer-grade cameras and linear spectral unmixing (Yang et al., 2007). Okraleaf cotton was evaluated in addition to conventional cotton in 2014 because the relatively sparse canopy of okraleaf cotton has been known to allow increased penetration of solar radiation, which heats and dessicates weevil-infested cotton squares that have abscised and fallen to the soil surface. Our objective was to quantify the likelihood of detecting individual cotton plants within diverse crop and weed plots.

\section{Materials and Methods}

In late June 2012, several individual regrowth cotton plants (Delta Pine DP1048, Monsanto Corp., St. Louis, MO, USA) or small clusters of adjacent cotton plants ( $N=133)$ were identified in a weedy fallow plot at a research field in Burleson County, TX. Geographic coordinates of the regrowth cotton plants were obtained at an absolute accuracy of $\leq 20 \mathrm{~cm}$ using a Trimble GPS Pathfinder ProXRT receiver (Trimble Navigation, Ltd., Sunnyvale, CA, USA) with the Wide Area Augmentation System (WAAS) correction. Height, width, and largest fruit type were recorded for each regrowth cotton plant or clusters of plants.

We planted conventional (Phytogen PHY499, Dow AgroSciences, Indianapolis, IN) and okraleaf (Fibermax FM8279, Bayer CropScience, Research Triangle Park, NC, USA) cotton plants at a seed spacing 
of $10 \mathrm{~cm}$ ( 4 inches) and row spacing of $1.02 \mathrm{~m}$ (40 inches) in a research field in Burleson County, TX, USA, on 17 April 2014. The field was occasionally irrigated to sustain plant growth. Each crop was planted in 53-m (173.9-ft) plots within 16-row blocks replicated three times. Corn (Integra A1013698, Integra Seed, Ames, IA, USA) was planted on 17 March 2014 and milo (Pioneer 84P80, Dupont Pioneer, Johnston, IA, USA) were planted on 20 March 2014 and soybeans (Pioneer 94Y90, Dupont Pioneer, Johnston, IA, USA) were planted on 27 March 2014. Cotton plots and volunteer cotton plants (16 conventional cotton (CC) plants and 16 okraleaf cotton (OLC) plants randomly assigned to rows in two transects per plot (Fig. 1)) were planted in soybean (S), corn (C), milo (M), fallow (F), and tilled (T) plots on 15 April 2014. We applied the term "fallow" to describe a weedy plot that had been plowed and left unseeded for one growing season. Height, width, and growth stage were recorded for each volunteer cotton plant and non-cotton plant along all transects.

Aerial images of the research field were obtained on 29 June 2012, and on 15 May 2014 (Early period), 6 June 2014 (Mid period), and 30 June 2014 (Late period). We equipped a Cessna 206 fixed-wing aircraft with two nadir-oriented Canon 5D Mark II digital cameras (Canon U.S.A., Melville, NY), which captured 21-megapixel images defined by a 5616 × 3744 array of 16-bit pixels (Yang et al., 2014). One camera recorded a color image (broadband red-green-blue, RGB) (ISO 200, 2-ms exposure, f/10), and a second camera recorded a near-infrared image (broadband NIR) (ISO 200, 2-ms exposure, f/14). The spectral bands were 400-500 nm (blue), 500-600 nm (green), 600-700 nm (red), and 720-1000 nm (NIR). We acquired airborne multispectral images from an altitude of approximately $305 \mathrm{~m}$ above ground level (AGL) to cover a viewing area of $561.6 \mathrm{~m} \times 374.4 \mathrm{~m}$ (0.1-m pixel ground resolution) (Westbrook et al. 2015). We placed four reference tarps of known reflectivity $(4 \%, 16 \%, 32 \%$, and $48 \%)$ within the field of view of each airborne multispectral image to establish a regression fit between measured spectral reflectance (absolute digital number, DN) and reflectivity (\%) for each spectral band.

Images acquired on 29 June 2012 images were geo-referenced using a geo-referenced image for 5 July 2012. Locations of regrowth cotton plants were collected in WGS84 projection and converted to the UTM83Z14 projection of the image files. The relative position of individual plants in geo-referenced images was achieved at an accuracy $\leq 5 \mathrm{~cm}$ in 2012 and 2014. In 2014, we acquired global positioning system (GPS) coordinates of nine ground control points $(0.41-\mathrm{m} \times 0.41-\mathrm{m}$ white boards) around the research plots at Field 14 on 15 May 2014 and 29 May 2014. Only eight of the ground control points were available on subsequent dates in 2014 due to the loss of one reference stake.

Images acquired in 2014 were geo-referenced using ArcGIS Desktop Version 10.2.2 (Esri, Redlands, CA, USA). Images were imported as *. TIF files created from the RAW CR2 camera format using Photoshop version 5.5. The white board locations were imported as a point vector file. The 15 May 2014 images were geo-referenced using the point vector file and a quadratic equation with residuals $\leq 3 \mathrm{~cm}$. All of the other images were geo-referenced using the 15 May 2014 color image with quadratic equations and residuals $\leq 5 \mathrm{~cm}$.

All geo-referenced images from 2012 and 2014 were saved as Erdas Imagine format files in ArcGIS (Esri, Redlands, CA, USA) and imported to IDRISI Selva (Clark Labs, Worcester, MA, USA) using the ERDIDRIS module. Raster files created in IDRISI were used to analyze and test the identification of individual 
regrowth cotton plants. Images acquired in 2012 were clipped to the area of interest (AOI) in which 113 individual (or clusters of) regrowth cotton plants were randomly distributed. Images acquired in 2014 were clipped to the area encompassing 63 individual plots. The clipped images were used for faster and more efficient analysis.

Analysis and identification of individual cotton plants was performed using the UNMIX module, selecting the Linear Spectral Unmixing (LSU) utility for 2012 images and Exhaustive Search Unmixing (ESU) utility for 2014 images. The UNMIX module performed sub-pixel classification. The LSU and ESU utilities required development of signature files containing spectral band endmember digital number (DN) values of vegetation and soil. The LSU utility cannot process more endmembers than available image bands. In this case, there were four spectral bands and four endmembers. However, the ESU utility can process more endmembers than bands, but only at the number of spectral bands per analytical run. Both the LSU and ESU utilities produce values of percent likelihood that a medium (i.e., cotton plant) is responsible for the composite spectral reflectance within a pixel. Spectral matching was performed after selecting a likelihood threshold (0.7 for regrowth plants in 2012, and 0.1 for volunteer plants in 2014) for the LSU and ESU values of cotton plants.

The 2012 analysis was performed using three endmember signature files. The three endmembers were for feature classes of cotton, soil, and non-cotton vegetation. We generated spectral endmember sets from 60 pixels of cotton, corn, milo, and soybean plants and bare soil from an airborne multispectral image (0.1-m pixel ground resolution), and from mean broadband color and NIR values (blue: 400-500 $\mathrm{nm}$, green: $500-600 \mathrm{~nm}$, red: 600-700 nm, NIR: 720-900 nm) extracted from ground-based hyperspectral measurements (Fieldspec Handheld2, Analytical Spectral Devices, Inc., Boulder, CO, USA) of five prevalent weed species (turnipweed, spotted spurge, velvetleaf, morningglory, and melonette). Mean values for each non-cotton vegetation type were pooled to derive spectral endmembers for the noncotton vegetation feature class. The modal DN value for each spectral band was assigned as the endmember of each feature class (Fig. 2). The ENDSIG module was used to create spectral signatures for cotton, soil, and non-cotton vegetation. These spectral signatures were added to a signature file created with the Collection Editor in IDRISI. The UNMIX LSU utility analyzed the windowed image for 2012 using the spectral signature file. We selected a threshold of 0.5 for the spectral matching logistic regression equation, which assigned an expected value of either conventional cotton or okraleaf cotton relative when the estimated relative contribution exceeded the threshold for the respective cotton type.

The resulting three raster files were real-value representations of the image with pixel values from 0.0 1.0 for each feature class. These derived pixel values indicated the relative contributions of each feature class.

The 2014 analysis was performed using eight endmembers and six spectral "bands". In addition to the red, green, blue, and NIR (red channel), two spectral "bands" were included for NIR in the green and blue channels (representing a minor portion of incoming radiation that passed through the NIR high pass filter). Spectral endmembers were derived for eight feature classes: fallow, tilled, okraleaf cotton, milo, soybean, corn, conventional cotton, and soil for each flight. The spectral endmembers for each feature class were computed by combining the modal DN values from six reference plots of okraleaf cotton and 
conventional cotton, and three reference plots of each of the other feature classes. Histograms for the reference plots were created and spectral endmembers were obtained in the same manner as the spectral endmembers in 2012. The ENDSIG module was used to create a signature for each feature class from which the Collection Editor created a signature file. The UNMIX ESU utility was run on the windowed images using eight signature files in 2014. The resulting eight raster files were real-value representations of the image with pixel values from $0.0-1.0$. We selected a threshold of 0.5 for the spectral matching logistic regression equation, which assigned an expected value of either conventional cotton or okraleaf cotton relative when the estimated relative contribution exceeded the threshold for the respective cotton type.

Our prior research (Westbrook et al. 2014) revealed that accuracy in detecting regrowth cotton plants improved with increasing plant width, maintaining a close correlation between width and height of regrowth cotton plants. In the present field study, it was critical to measure the width and height of volunteer cotton plants because these plants develop distinctively within the various environments due to differences in insolation, soil moisture, and soil nutrients. Differences of plant height and plant width were analyzed using Proc ANOVA (SAS 9.4, SAS Institute, Inc., Cary, NC, USA). Mean separation of plant height and plant width between observation periods and plots was obtained using the Tukey adjustment at a significance level of $\alpha=0.05$.

For both 2012 and 2014 images, we evaluated the skill of the spectral matching technique using linear spectral unmixing in locating individual cotton plants from the output raster files. The skill was calculated as a contingency score of correctly identifying a cotton plant or non-cotton plant. A buffer radius of $0.25 \mathrm{~m}$ was created around geo-referenced plant locations from which to select approximately 20 pixels from the output raster files. Using the EXTRACT module, buffered plant locations were overlayed on output raster files to extract pixel values for each buffered plant. Output from the EXTRACT module was imported into Excel 2010 (Microsoft, Redmond, WA, USA) for data management. For the 2012 field data, we selected all (113) regrowth cotton plants and 113 randomly selected noncotton locations (each representing all pixels within a $0.25-\mathrm{m}$ radius) within the field $\mathrm{AOI}$. We applied the Fit $Y$ by $X$ utility in JMP 11.2.0 (SAS Institute, Inc., Cary, NC, USA) to 44 regrowth cotton plants and 57 non-cotton locations (training data set) to calculate the logistic regression fit between observed plant type (regrowth conventional cotton plants versus non-cotton plants) and the proportion of pixels with an $L S U$ value for conventional cotton $\left(L S U_{C C}\right) \geq 0.7$. We applied the Fit $Y$ by $X$ utility in JMP 11.2.0 to apply the training logistic regression fit to evaluate an independent validation data set of 69 regrowth cotton plants and 56 non-cotton plants for the 2012 field data. We applied the Fit Model utility (selecting a generalized linear model, binomial distribution, logit link function, and Firth bias-adjusted estimates) in JMP 11.2.0 (SAS Institute, Inc., Cary, NC, USA) to calculate the logistic regression between observed plant type (volunteer conventional cotton plants and okraleaf cotton plants versus non-cotton plants) and the proportion of pixels with an $E S U_{C C}$ (and $E S U_{O L C}$ ) $\geq 0.1$ in 2014. The $E S U_{C C}$ (or $E S U_{O L C}$ ) value is the exhaustive search unmixing (ESU) value indicating the likely proportion of spectral reflectance due to conventional cotton (CC) (or okraleaf cotton (OLC)). We assigned the term $E S U_{C C} \geq 0.1$ when we selected a threshold of 0.1 for the likely proportion of spectral reflectance due to conventional cotton. 
Subsequently, we estimated the skill in applying trained logistic regression to randomly-selected validation sets of volunteer and regrowth cotton plants using the Fit $\mathrm{Y}$ by $\mathrm{X}$ utility (contingency analysis) in JMP 11.2.0 (SAS Institute, Inc., Cary, NC, USA).

\section{Results and Discussion}

For the multispectral imaging on 29 June 2012, reference tarps were unavailable to calculate percent reflectivity so we calculated spectral endmember data for cotton, mixed weeds, and soil based on DN values (Table 1). Logistic regression of a training data set of regrowth cotton plants $(\mathrm{N}=44)$ and noncotton plants $(\mathrm{N}=57)$ versus the proportion of pixels with $\mathrm{ESU}_{\mathrm{CC}} \geq 0.7$ resulted in a logit of $\mathrm{Y}=-1.45+3.69 \mathrm{X}$. The fit of the logistic regression was significant $\left(L R \chi^{2}=30.80 ; d f=1 ; P<0.001\right)$, and resulted in a misclassification rate of 0.238 . Contingency analysis of the validation data set $(N=125)$ was significant $\left(L R \chi^{2}=27.286 ; d f=1 ; P<0.001\right)$, and resulted in 0.65 true positives, 0.35 false positives, 0.80 true negatives, 0.20 false negatives, and 0.28 misclassification.

A visual example of the image analysis results for one block of the tilled section of the research field are described for 30 June 2014. A color image of the entire research field shows the seven feature sections, each with three blocks and three plots per block (Fig. 3). Block 1 of the tilled section is highlighted by a red rectangle, which is extracted for further examination in Fig. 4. The first plot contains individual volunteer okraleaf cotton plants, the second plot contains individual volunteer conventional cotton plants, and the third plot is a reference plot without cotton plants. The ESU model estimated the likelihood that volunteer cotton plants were located in particular rows of two transects across the plots, with the cyan and red symbols indicating true positives and true negatives, respectively.

For measurements of volunteer conventional cotton plants in 2014 , analysis of variance revealed a significant model $(F=331.90 ; d f=14,663 ; P<0.001)$ for height of volunteer conventional cotton plants with significant main effects of period $(F=1742.17 ; d f=2 ; P<0.001)$ and plot $(F=81.05 ; d f=4 ; P<0.001)$, and interaction of period and plot $(F=104.75 ; d f=8 ; P<0.001)$. Significant main effects (period: $F=1739.18$; $d f=2 ; P<0.001$ and plot: $F=264.02 ; d f=4 ; P<0.001)$ and their interaction $(F=180.01 ; d f=8 ; P<0.001)$ were associated with the significant ANOVA model $(F=426.75 ; d f=14,663 ; P<0.001)$ for width of volunteer conventional cotton plants. The Waller-Duncan K-ratio test revealed that height of volunteer conventional cotton plants increased significantly between each successive observation period from $10.3 \mathrm{~cm}$ to $20.9 \mathrm{~cm}$ and $46.7 \mathrm{~cm}$ in the Early, Mid, and Late periods, respectively. Cotton plant width increased significantly between each successive observation period from $7.3 \mathrm{~cm}$ to $17.8 \mathrm{~cm}$ and $40.8 \mathrm{~cm}$ in the Early, Mid, and Late periods, respectively. The smallest mean height and width values of volunteer conventional cotton plants were associated with corn plots and largest values with tilled plots. Volunteer conventional cotton plants in milo and soybean plots were of similar mean height, and of similar height and width in soybean and fallow plots.

For measurements of volunteer okraleaf cotton plants in 2014, analysis of variance of the height of volunteer okraleaf cotton plants in plots of five feature classes revealed overall significance $(F=482.32$; $d f=14,699 ; P<0.001)$, main effects (period: $F=2506.13 ; d f=2 ; P<0.001$ and plot $(F=172.76 ; d f=4 ; P<0.001)$ and their interaction $(F=131.14 ; d f=8 ; P<0.001)$. Similarly, the overall model $(F=499.90 ; d f=14,699$; 
$P<0.001)$, main effects (period: $F=2055.90 ; d f=2 ; P<0.001)$, plot $(F=354.48 ; d f=4 ; P<0.001)$, and their interaction $(F=183.61 ; d f=8 ; P<0.001)$ were significant for width of volunteer okraleaf cotton plants. Mean height of volunteer okraleaf cotton plants increased significantly between each successive period from $5.6 \mathrm{~cm}$ to $16.8 \mathrm{~cm}$ and $43.4 \mathrm{~cm}$ in the Early, Mid, and Late periods, respectively. Width of volunteer okraleaf cotton plants increased significantly from $6.2 \mathrm{~cm}$ to $16.7 \mathrm{~cm}$ and $37.5 \mathrm{~cm}$ for the Early, Mid, and Late periods, respectively.

The use of reference tarps allowed us to calculate proportional spectral reflectivity of reference plots (Table 2). Proportional spectral reflectivity values for red, green, blue, and NIR wavebands represent the DN values that comprise endmembers of the seven feature classes and soil associated with each plot. We report spectral reflectivity based on modal rather than extreme values due to Bayer pattern interpolation of mixed-feature pixels by commercial-grade cameras. Therefore, our estimates of spectral reflectivity are conservative for vegetation and soil feature classes.

Logistic regression of observed and estimated likelihood of volunteer conventional cotton plants is shown in Table 3. Using a selection criterion of $E S U_{C C} \geq 0.1$ to select the proportion of pixels within a radius of $0.25 \mathrm{~m}$ around the volunteer plants, the training data sets resulted in significant estimators of voluntary conventional cotton plants in frequently tilled plots in the Mid and Late periods; in soybean plots in the Early period; and in corn plots in the Late period. However, after the trained classification was applied to a validation data set, significant estimates were found for volunteer conventional cotton plants in tilled plots in Mid and Late periods; in soybean plots in the Late period; and in corn plots in the Late period. The misclassification rate for the significant validation estimates of volunteer conventional cotton plants ranged from 0.146 to 0.313 . Volunteer conventional cotton plants in the validation data set were not significantly estimated in the Early period, although they were for the training data set in the soybean plot.

Likelihood estimates of volunteer okraleaf cotton plants at a threshold of $E S U_{O L C} \geq 0.1$ are presented in Table 4. Significant estimates for training data sets of volunteer okraleaf cotton plants were found in tilled plots in the Mid and Late periods; in soybean plots in the Early, Mid, and Late periods; in milo plots in the Early period; and in corn plots in the Early and Late periods. However, after the trained classification was applied to a validation data set estimates were no longer significant for okraleaf cotton plants in milo and soybean plots in the Early period, but were significant for corn in the Mid period as well as for other period*plot combinations that were significant for the training data set. The misclassification rate for the significant validation estimates of volunteer okraleaf cotton plants ranged from 0.125 to 0.292 .

Detection of cotton plants in the Early and Mid periods is especially informative for boll weevil eradication program officials because the cotton plants were in the vegetative or pinhead square stage (i.e., pre-blooming), before they would be suitable hosts for boll weevils.

\section{Conclusions}

Airborne multispectral imaging using consumer-grade cameras successfully identified individual preblooming volunteer cotton plants in frequently tilled, milo, and soybean plots in several cases. Aside 
from spectral characteristics of cotton plants and other crop, ground cover, or soil features, differences of cotton plant growth in these environments affects the relative size of cotton plants and adjacent crops and weeds. Differences in plant growth resulted in greatest detection accuracy in frequently tilled plots and least detection accuracy in weedy fallow, corn, and milo plots. The capability to detect individual pre-blooming volunteer cotton plants can benefit the mapping, trapping, and management of fields infested with volunteer cotton plants. Airborne remote sensing of cotton fields and volunteer and regrowth cotton plants within large regions may provide a supplementary revenue opportunity for aerial applicators. Further, the capability to detect all stages of individual volunteer and regrowth cotton plants, as well as unreported production cotton fields, can benefit boll weevil eradication efforts to eliminate non-compliant cotton fields.

The spectral matching technique was applied to generate likelihood estimates of the presence of individual cotton plants. Boll weevil eradication program officials and others can specify their unique detection threshold criteria in applying this technique to estimate the likelihood of detection of cotton plants in fields. Specification of detection threshold criteria will alter the relationship of the contingency analysis (i.e., true positives, false positives, true negatives, and false negatives). For example, decisionmakers may select a threshold that increases the proportion of true positives (which inadvertently increases the proportion of false positives). The present value of the spectral unmixing technique using multispectral images acquired by consumer-grade cameras is based on the relative likelihood that cotton plants are located in one field versus another, information that can be used by boll weevil eradication officials to direct personnel and other pest management resources.

Bayer pattern interpolation of image pixels limits the use of image detection of plants that are represented by fewer than approximately 20 pixels. Pixel value interpolation affects both the calculation of spectral endmembers and the application of the spectral endmembers in the LSU detection algorithm. Use of cameras with independent image sensors for each spectral band will obviate the need for image pixel interpolation techniques, and is expected to significantly improve the accuracy in detecting individual cotton plants at earlier growth stages.

\section{References}

Bai, J., Li, J., Li, S., 2011. Monitoring the plant density of cotton with remotely sensed data. In: Computer and Computing Technologies in Agriculture IV, Li, D., Liu, Y., Chen, Y. (Eds.), Advances in Information and Communication Technology 345, International Federation for Information Processing, Beijing, China, pp. 90-101. http://dx.doi.org/10.1007/978-3-642-18336-2

Summy, K.R., Heilman, M.D., Namken, L.N., Hart, W.G., 1986. Control of boll weevils (Coleoptera: Curculionidae) through crop residue disposal: Destruction of subtropical cotton under inclement conditions. J. Econ. Entomol. 79, 1662-1665. http://dx.doi.org/10.1093/jee/79.6.1662

Troxclair, N., 2010. Unique situations and challenges for the Texas Boll Weevil Eradication Program in the Winter Garden area of Texas. National Cotton Council, Memphis, TN. Proc. Beltwide Cotton Conf., pp. 1024-1026. 
Westbrook, J.K., Suh, C.P.-C., Yang, C., Lan, Y., Eyster, R.S., 2015. Airborne multispectral detection of regrowth cotton fields. J. Appl. Rem. Sens. 9:096081, 1-11. http://dx.doi.org/10.1117/1.JRS.9.096081

Yang, C., Everitt, J.H., Bradford, J.M., 2007. Using multispectral imagery and linear spectral unmixing techniques for estimating crop yield variability. Trans. ASABE 50, 667-674. http://dx.doi.org/10.13031/2013.22658

Yang, C., Greenberg, S.M., Everitt, J.H., Fernandez, C.J., 2011. Assessing cotton defoliation, regrowth control and root rot infection using remote sensing technology. Int. J. Agric. Biol. Eng. 4(4), 1-11.

Yang, C., Westbrook, J.K., Suh, C.P.-C., Martin, D.E., Hoffmann, W.C., Lan, Y., Fritz, B.K., Goolsby, J.A., 2014. An airborne multispectral imaging system based on two consumer-grade cameras for agricultural remote sensing. Remote Sens. 6, 5257-5278. http://dx.doi.org/10.3390/rs6065257

Zhang, H., Lan, Y., Suh, C.P., Westbrook, J.K., Lacey, R., Hoffmann, W.C., 2012. Differentiation of cotton from other crops at different growth stages using spectral properties and discriminant analysis. Trans. ASABE 55, 1623-1630. http://dx.doi.org/10.13031/2013.42229

Zhang, H., Lan, Y., Suh, C.P., Westbrook, J.K., Hoffmann, W.C., Yang, C.H., Huang, Y.B., 2013. Fusion of remotely sensed data from airborne and ground-based sensors to enhance detection of cotton plants. Comput. Electron. Agric. 93, 55-59. http://dx.doi.org/10.1016/j.compag.2013.02.001

\section{Acknowledgments}

We thank the Cotton Foundation (general project \#5002-009-00) and Cotton Inc. (core project \#10-776) for funding this project, and Mike O'Neil, Fred Gomez, Lee Denham, and Derrick Hall for their technical assistance. Mention of trade names or commercial products in this article is solely for the purpose of providing specific information and does not imply recommendation or endorsement by the U.S. Department of Agriculture. USDA is an equal opportunity provider and employer. 
Table 1. Spectral endmember sets for feature classes at a research plot of regrowth cotton plants in Burleson County, TX, USA on 29 June 2012.

\begin{tabular}{lccrc}
\hline & \multicolumn{4}{c}{ Band } \\
\cline { 2 - 5 } \multicolumn{1}{c}{ Feature } & Red & Green & Blue & NIR \\
\hline Cotton & 10909 & 13646 & 8763 & 37805 \\
Weeds & 13673 & 22133 & 20629 & 35264 \\
Soil & 16707 & 20507 & 26879 & 22689 \\
\hline
\end{tabular}


Table 2. Proportional spectral reflectivity ${ }^{a}$ of plots at a research field in Burleson County, TX, USA in 2014.

\begin{tabular}{|c|c|c|c|c|c|c|c|c|c|c|c|c|c|c|c|}
\hline \multirow[b]{3}{*}{ Period $^{b}$} & \multirow[b]{3}{*}{ Band } & \multicolumn{10}{|c|}{ Okraleaf } & \multirow{2}{*}{\multicolumn{2}{|c|}{ Corn }} & \multicolumn{2}{|c|}{ Conventional } \\
\hline & & \multicolumn{2}{|c|}{ Fallow } & \multicolumn{2}{|c|}{ Tilled } & \multicolumn{2}{|c|}{ Cotton } & \multicolumn{2}{|c|}{ Milo } & \multicolumn{2}{|c|}{ Soybean } & & & \multicolumn{2}{|c|}{ Cotton } \\
\hline & & Soil & Veg & Soil & Veg & Soil & Veg & Soil & Veg & Soil & Veg & Soil & Veg & Soil & Veg \\
\hline Early & Blue & 0.106 & 0.079 & 0.109 & 0.083 & 0.117 & 0.097 & 0.107 & 0.064 & 0.109 & 0.086 & 0.097 & 0.078 & .141 & 0.115 \\
\hline Early & Green & .108 & .079 & 109 & & 19 & 01 & 113 & 777 & 15 & & 106 & 90 & & 118 \\
\hline Early & Red & 0.099 & 0.073 & 0.102 & 0.092 & 0.111 & 0.092 & 0.096 & 0.056 & 0.102 & 0.068 & 0.106 & 0.079 & 0.133 & 0.111 \\
\hline Early & NIR & 0.184 & 0.225 & 0.190 & 0.250 & 0.214 & 0.263 & 0.221 & 0.316 & 0.229 & 0.303 & 0.223 & 0.316 & 0.222 & 0.281 \\
\hline Mid & Blue & 0.106 & 0.057 & 0.075 & & 0.077 & 0.062 & & & 0.085 & & 0.102 & & .079 & 0.057 \\
\hline Mid & Green & 0.110 & 0.074 & 0.079 & 0.065 & 0.094 & 0.080 & 0.085 & 0.073 & 0.095 & 0.068 & 0.108 & 0.072 & .097 & 0.074 \\
\hline Mid & Red & 26 & & & & & & & & 04 & & & & & 79 \\
\hline Mid & & 0.211 & 0.310 & 0.152 & & & & 0.243 & 0.313 & 0.209 & 0.352 & 0.179 & 0.276 & 0.195 & 0.354 \\
\hline Late & Blue & 0.101 & 0.039 & 0.096 & 0.067 & 0.079 & 0.043 & 0.054 & 0.043 & 0.072 & 0.039 & 0.089 & 0.042 & 0.063 & 0.039 \\
\hline Late & Green & 0.116 & 0.065 & 0.102 & 0.079 & 0.086 & 0.067 & 0.080 & 0.069 & 0.085 & 0.054 & 0.102 & 0.061 & 0.082 & 0.053 \\
\hline Late & Red & 0.107 & 0.051 & 0.118 & 0.092 & 0.085 & 0.055 & 0.081 & 0.071 & 0.096 & 0.047 & 0.113 & 0.076 & 0.079 & 0.055 \\
\hline Late & NIR & 0.261 & 0.320 & 0.179 & 0.265 & 0.188 & 0.346 & 0.198 & 0.245 & 0.190 & 0.247 & 0.152 & 0.216 & 0.180 & 0.357 \\
\hline
\end{tabular}

${ }^{a}$ Modal digital number (DN) spectral reflectance values of soil and vegetation (Veg) in reference plots of each feature class were extracted from DN historgrams for each spectral band. Reflectivity values were calculated using quadratic regression (with forced zero-intercept) of DN values and assigned reflectivity values of reference reflectance tarps.

${ }^{\mathrm{b}}$ Early = 15 May; Mid = 6 June; Late $=30$ June 
Table 3. Logistic regression of the proportion of pixels with $E S U_{C C} \geq 0.1$ per individual volunteer conventional cotton plant within specific non-cotton plots at a research field in Burleson County, TX, USA in 2014.

\begin{tabular}{|c|c|c|c|c|c|c|}
\hline \multirow[b]{2}{*}{ Period } & \multirow[b]{2}{*}{ Plot } & \multicolumn{3}{|c|}{ Training } & \multicolumn{2}{|c|}{ Validation } \\
\hline & & logit & $L R \chi^{2}$ & $\begin{array}{c}\text { Misclassification } \\
\text { Rate }\end{array}$ & $\operatorname{LR} \chi^{2}$ & $\begin{array}{c}\text { Misclassification } \\
\text { Rate }\end{array}$ \\
\hline Early & Corn & $Y=0.07+0.33 X$ & 0.12 & 0.457 & $<0.01$ & 0.521 \\
\hline Early & Fallow & $Y=0.46+0.003 X$ & $<0.01$ & 0.383 & $<0.01$ & 0.596 \\
\hline Early & Milo & $Y=-0.01+0.10 X$ & $<0.01$ & 0.479 & 0.02 & 0.521 \\
\hline Early & Soybean & $Y=0.66-1.75 X$ & $4.03 *$ & 0.378 & 3.04 & 0.652 \\
\hline Early & Tilled & $Y=0.60-5.08 X$ & 3.29 & 0.362 & 0.51 & 0.468 \\
\hline Mid & Corn & $Y=0.80-1.64 X$ & 2.30 & 0.417 & 1.54 & 0.426 \\
\hline Mid & Fallow & $Y=0.12+3.79 X$ & 0.54 & 0.457 & $<0.01$ & 0.511 \\
\hline Mid & Milo & $Y=0.64-2.56 \mathrm{X}$ & 2.23 & 0.396 & 0.80 & 0.563 \\
\hline Mid & Soybean & $Y=-0.26+4.48 X$ & 3.02 & 0.313 & $<0.01$ & 0.511 \\
\hline Mid & Tilled & $Y=0.85-74.33 X$ & $23.00 *$ & 0.213 & $8.27^{*}$ & 0.313 \\
\hline Late & Corn & $Y=-0.80+9.60 X$ & $10.35^{*}$ & 0.234 & $17.40^{*}$ & 0.208 \\
\hline Late & Fallow & $Y=0.63-1.36 X$ & 0.98 & 0.489 & 0.11 & 0.511 \\
\hline Late & Milo & $Y=0.01-0.18 X$ & $<0.01$ & 0.500 & 1.58 & 0.404 \\
\hline Late & Soybean & $Y=0.23-1.17 X$ & 0.45 & 0.383 & $7.15^{*}$ & 0.304 \\
\hline Late & Tilled & $Y=2.66-44.06 X$ & $49.63^{*}$ & 0.087 & $27.18^{*}$ & 0.146 \\
\hline
\end{tabular}

$E S U_{C C}=$ exhaustive search unmixing of reflectance from conventional cotton plants; $L R \chi^{2}=$ likelihood ratio chi-square; $Y=$ logit value; $X=$ proportion of pixels with $E S U_{c C} \geq 0.1 ;^{*}=$ significant at $P<0.05$ 
Table 4. Logistic regression of the proportion of pixels with $E S U_{O L C} \geq 0.1$ per individual volunteer okraleaf cotton plant within specific non-cotton plots at a research field in Burleson County, TX, in 2014.

\begin{tabular}{lllrrrr}
\hline & & \multicolumn{3}{c}{ Training } & \multicolumn{2}{c}{ Validation } \\
\cline { 3 - 7 } Period & Plot & \multicolumn{1}{c}{ logit } & \multicolumn{1}{c}{$L R \chi^{2}$} & Misclassification & Rate & \multicolumn{1}{c}{ Misclassification } \\
Early & Corn & $Y=-0.83+13.37 \mathrm{X}$ & $10.98^{*}$ & 0.354 & $12.75^{*}$ & 0.271 \\
Early & Fallow & $\mathrm{Y}=-0.02+1.02 \mathrm{X}$ & 0.02 & 0.479 & $<0.01$ & 0.500 \\
Early & Milo & $\mathrm{Y}=-0.04+22.48 \mathrm{X}$ & $4.95^{*}$ & 0.396 & $<0.01$ & 0.500 \\
Early & Soybean & $\mathrm{Y}=-0.25+30.52 \mathrm{X}$ & $5.08^{*}$ & 0.396 & 0.01 & 0.532 \\
Early & Tilled & $\mathrm{Y}=-0.12-3.11 \mathrm{X}$ & 0.11 & 0.458 & $<0.01$ & 0.458 \\
Mid & Corn & $\mathrm{Y}=-0.32+1.67 \mathrm{X}$ & 0.76 & 0.458 & $7.28^{*}$ & 0.313 \\
Mid & Fallow & $\mathrm{Y}=-0.06-2.73 \mathrm{X}$ & 0.07 & 0.479 & $<0.01$ & 0.521 \\
Mid & Milo & $\mathrm{Y}=0.31-1.42 \mathrm{X}$ & 0.88 & 0.396 & 0.02 & 0.542 \\
Mid & Soybean & $\mathrm{Y}=-1.71+7.54 \mathrm{X}$ & $7.02^{*}$ & 0.167 & $23.02^{*}$ & 0.167 \\
Mid & Tilled & $\mathrm{Y}=1.37-40.41 \mathrm{X}$ & $33.84^{*}$ & 0.125 & $35.32^{*}$ & 0.125 \\
Late & Corn & $\mathrm{Y}=-0.90+4.32 \mathrm{X}$ & $8.34^{*}$ & 0.319 & $8.88^{*}$ & 0.292 \\
Late & Fallow & $\mathrm{Y}=0.08-0.77 \mathrm{X}$ & 0.38 & 0.375 & 0.95 & 0.438 \\
Late & Milo & $\mathrm{Y}=-0.29+0.86 \mathrm{X}$ & 0.77 & 0.447 & 0.09 & 0.521 \\
Late & Soybean & $\mathrm{Y}=0.15-1.83 \mathrm{X}$ & 0.92 & 0.396 & 0.53 & 0.542 \\
Late & Tilled & $\mathrm{Y}=1.39-5.84 \mathrm{X}$ & $21.10^{*}$ & 0.146 & $12.56^{*}$ & 0.250 \\
\hline
\end{tabular}

$E S U_{O L C}=$ exhaustive search unmixing of reflectance from okraleaf cotton plants; $L R \chi^{2}=$ likelihood ratio chi-square; $Y=$ logit value; $X=$ proportion of pixels with $E S U_{O L C} \geq 0.1 ;{ }^{*}=$ significant at $P<$ 0.05 


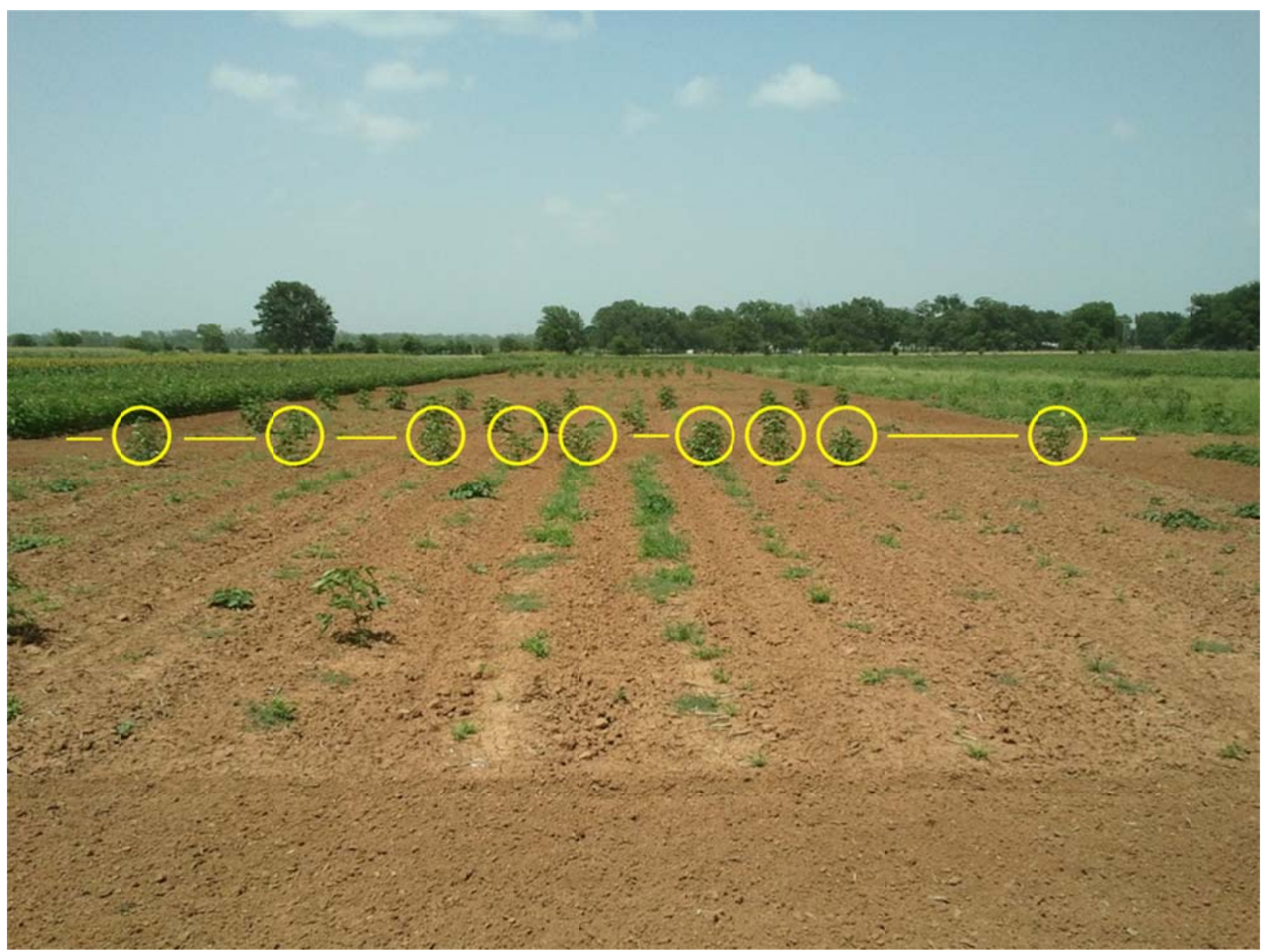

Figure 1. Volunteer conventional cotton plants located in random rows along a transect within a tilled plot at a research field in Burleson County, TX, USA on 30 June 2014. 


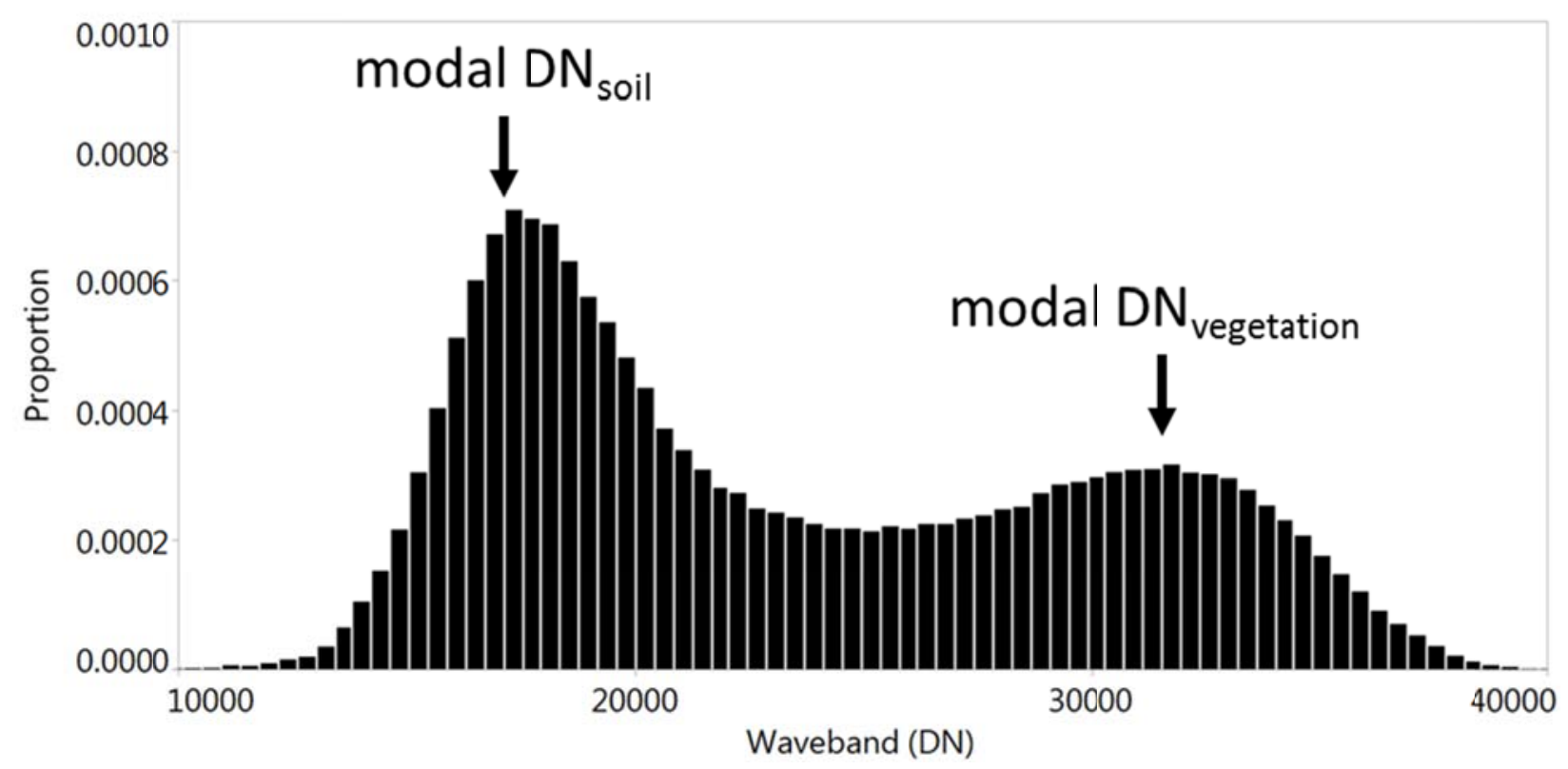

Figure 2. Histogram of the proportion of pixels with digital number (DN) for the near infrared (NIR) waveband of a 0.1-m pixel ground resolution image of reference conventional cotton plots in Burleson County, TX, USA on 30 June 2014. The bimodal distribution reveals a narrow peak at lower DN values for soil and a broad peak at the higher DN values for vegetation (conventional cotton). Histograms for the red, green, and blue wavelengths are similar in shape, but with vegetation at lower DN values and soil at higher DN values. Modal DN values are assigned as spectral endmembers for input to the linear spectral unmixing (LSU) and exhaustive search unmixing (ESU) calculations. 


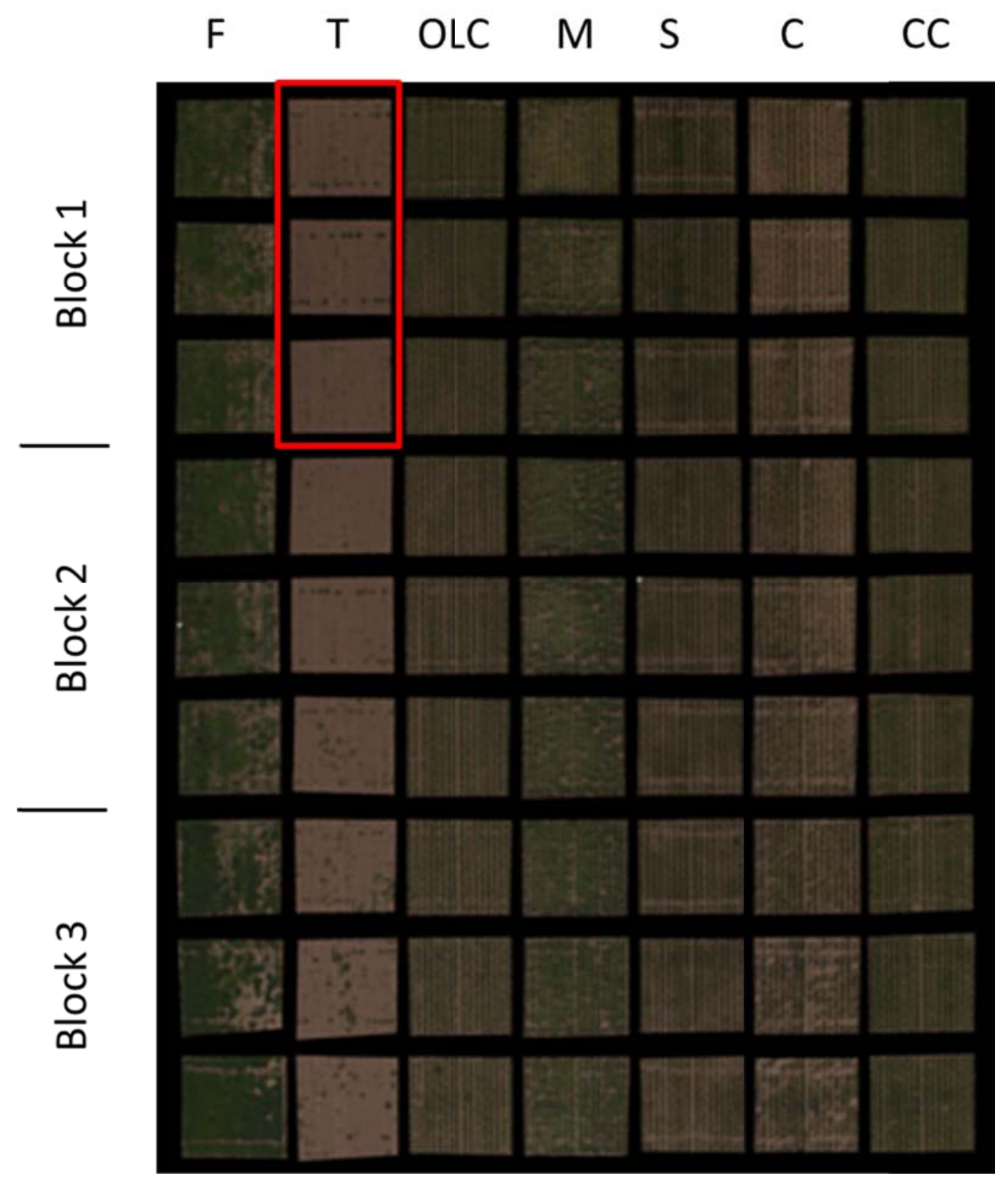

Figure 3. Color image (0.1-m pixel ground resolution) of a research field in Burleson County, TX, USA on 30 June 2014 with the following features: fallow (F), tilled (T), okraleaf cotton (OLC), milo (M), soybean (S), corn (C), and conventional cotton (CC). Each block within a feature class includes a plot without any volunteer cotton plants, a plot with 16 volunteer conventional cotton plants, and a plot with 16 volunteer okraleaf cotton plants. The red rectangle highlights Block 1 of the tilled section of the field. 


\section{(a)}

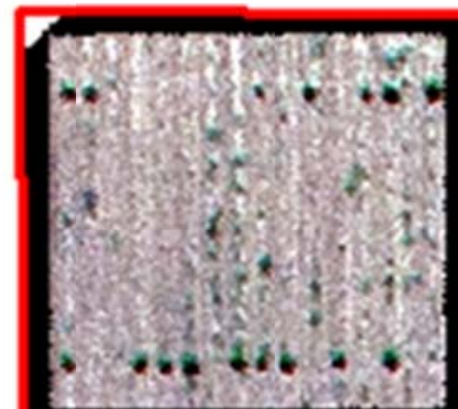

Okraleaf cotton

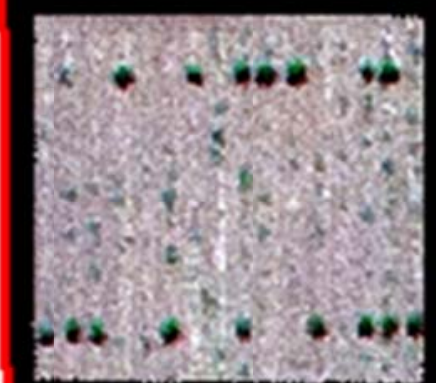

Conventional cotton

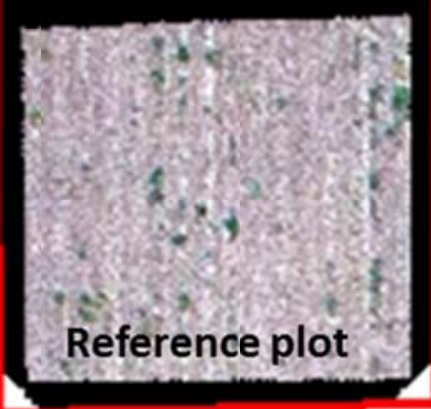

(b)

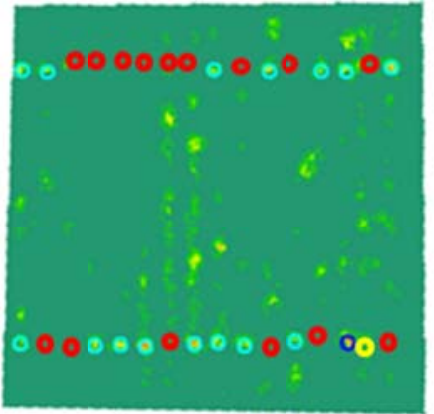

Okraleaf cotton

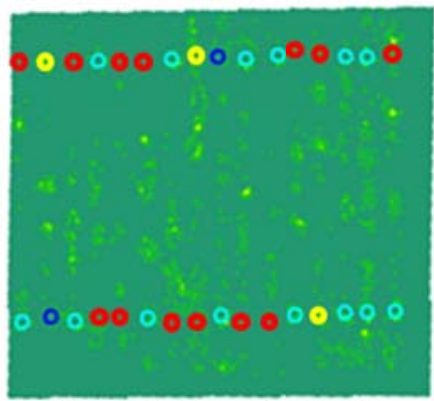

Conventional cotton

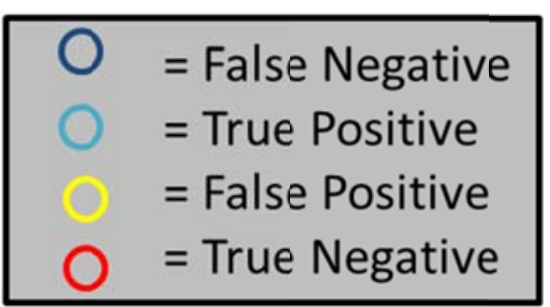

Figure 4. One block (as highlighted in Figure 3) of the tilled section of a research field in Burleson County, TX, USA on 30 June 2014: (a) color image (0.1-m pixel ground resolution) of a plot with 16 volunteer okraleaf cotton plants, a plot with 16 volunteer conventional cotton plants, and a reference plot without any volunteer cotton plants; and (b) estimates and validation of exhaustive search unmixing of individual volunteer conventional cotton plants $\left(E S U_{C C}\right)$ and of exhaustive search unmixing of individual volunteer okraleaf cotton plants $\left(E S U_{O L C}\right)$. 